\title{
Traumatic multiple rib fracture and patella ligaments rupture in an argentine parade horse-case report
}

\author{
U. M. Garba ${ }^{1}$, M. Bisalla ${ }^{2}$, A. Audu ${ }^{1}$, E. U. Onwuhafua ${ }^{1}$ \\ ${ }^{1}$ Veterinary Clinic, Equitation Wing, Nigerian Defence Academy, Kaduna, Nigeria \\ ${ }^{2}$ Department of Veterinary Pathology, Faculty of Veterinary Medicine, Ahmadu Bello University Zaria, Nigeria
}

\section{Email address:}

garbaum@yahoo.com(U. M. Garba)

\section{To cite this article:}

U. M. Garba, M. Bisalla, A. Audu, E. U. Onwuhafua. Traumatic Multiple rib Fracture and Patella Ligaments Rupture in an Argentine Parade Horse-Case Report. Animal and Veterinary Sciences. Vol. 1, No. 3, 2013, pp. 23-26. doi: 10.11648/j.avs.20130103.11

\begin{abstract}
The objective of reporting this case is to describe the clinical signs and postmortem findings associated with multiple rib fracture and patella ligaments rupture in a gelding used for ceremonial military parade with a view to improving diagnostic skill of practitioners for a quick and appropriate plan for managing chest and patella traumas. In this case, 7 years old, $500 \mathrm{~kg}$ body weight, Argentine gelding slipped off concreted stable-floor while it was being led out for a routine riding exercise. At the time of first presentation (19 hours post-accident), the clinical findings were; congested bilateral ocular mucous membranes with jaundice, base-wide conformation of forelimbs, head nodding, bilateral twitching around shoulders, reluctance to move, off-feed and refusal to drink water. Hyperpnoea, tachycardia and hyperthermia were also observed. There were no evidences of bruises, swellings or localized pain on general inspection and palpation at the time of presentation. In subsequent days groaning, teeth grinding, intermittent sternal recumbency and 'dog sitting' position were observed until the gelding died in early hours of day 6, post-accident. Postmortem findings were; proximal $3^{\text {rd }}$ undisplaced, simple fracture of ribs no. 2 to 18 (17 ribs) in the left hemithorax, jaundice, hemorrhagic thighs and stifles with ruptured left patella ligaments. Diagnosis of 'Traumatic multiple rib fracture and patella ligaments rupture was made at postmortem. In conclusion, it was suggested that when adult horse falls, thorough clinical examination, ultrasonography or less revealing radiography should be conducted while assessing thoracic and patella traumas in horses as some of the serious signs may not manifest at the time of accident. This will enable equine practitioners to plan early for conservative, surgical or medical management regime thereby reducing fatality.
\end{abstract}

Keywords: Traumatic, Ribs, Fracture, Patella, Rupture, Horse

\section{Introduction}

Blunt or penetrating traumas on the chest in horses from fall or crash into sharp objects may occur during racing, agitation of horses and at birth of a foal [1].

Generally, rib fractures are frequent in newborn foals especially at the costochondral junction which suggests that most thoracic traumas probably occur during parturition [2]. Ribs fracture also occur in adults horses but not common and are usually associated with traumatic events [3]. There may not be apparent respiratory dysfunction at onset as pointer to the condition leading to erroneous diagnosis, therefore, most cases are accurately diagnosed at postmortem [4]. Complications of thoracic trauma include pneumothorax, pneumomediastinum, hemothorax, pleuritis, diaphragmatic hernia, and damage to the lungs, heart, blood vessels, or abdomen and sudden death. Patient stabilization is the primary objective before conservative or surgical treatment. Deciding how to manage each case depends on many factors such as the location, type, extent of the injury, anesthetic concerns and response to initial treatment $[5,6]$.

This case involved an adult parade charger that was saddled in the loosebox and slipped off while being led out of the stable by a horseman for routine exercise. The objective of reporting this case is to describe the clinical signs and postmortem findings associated with multiple ribs fracture and patella ligaments rupture in an Argentine gelding used for ceremonial military parade with a view to improving diagnostic skill of practitioners for a quicker and appropriate managing plan for chest and patella traumas. 


\section{Clinical History}

A 7 years old Argentine gelding (castrated male horse) which suddenly slipped off the concreted-floor of stable corridor while it was being led out for a ride was presented, 19 hours after the accident to the Veterinary Clinic, Equitation Wing, Nigerian Defence Academy with the chief complaint of reluctance to move. The live body weight of the gelding was about $500 \mathrm{~kg}$. It was the number one ceremonial military parade horse. From the horseman's explanation, it fell on sternal recumbency with the forelimbs stretched-out forward such that elbows and stifles were directly on ground. It was not able to rise immediately, until it was gently supported to stand. The horseman led the gelding back into the loosebox as there was no observable superficial wound or fracture. The horse walked normally while it was led back into its loosebox.

\section{Clinical Examination}

The gelding stood with base-wide (feet spread-out) conformation of forelimbs, it nodded its head intermittently, muscles twitched around the shoulders bilaterally, and ocular mucous membranes were congested with slight jaundice. The horse was reluctant to move when prompted, off-feed and water. There were no evidences of bruises, swelling, or localized pain on general inspection and palpation of the back and limbs. Respiratory rate was 103 per minute (hyperpnoea), pulse was 97/min (tachycardia) and rectal temperature was $38.9{ }^{\circ} \mathrm{C}$ (hyperthermia) at first evaluation.

Inspection of the site of accident revealed that the stable corridor-floor was smooth due to several years of horses and human traffic.

\section{Tentative Diagnosis}

\section{Sprained Tendons}

\section{Plan}

Referral, if no improvement within 24 hours.

\section{Treatment}

On day 0 of treatment, medication was symptomatically started based on the tentative diagnosis as follows; Dexaphenylathrite ${ }^{\circledR}$ inj (Phenylbutazone $18 \mathrm{~g}$ and Dexamethasone $0.035 \mathrm{~g}$, Cedex, France), $11 \mathrm{ml}$ i.m. once daily for 2 days as recommended by the manufacturer.

Multivitamin inj. (Vitaflash $\AA$, Kepro B.V., Holland), $15 \mathrm{ml}$ intramuscularly once daily for 5 days as recommended by the manufacturer.

Dextrose saline-5\%, 1,000ml was administered by fast intravenous infusion.

The gelding was allowed to remain standing in the location it was treated since it could not walk when prompted.

On day 1, based on the suspicion of colic as a complicating factor, hyosine hydrochloride $60 \mathrm{mg}$ i.v. was administered to the horse twice at 6 hours intervals.

\section{Findings}

\subsection{Clinical Observations}

Five hours ( $5 \mathrm{hrs})$ post commencement of treatment, reevaluation of the vital parameters showed drop in the values of vital parameters but did not return to normal (Table.1), forefeet were positioned closer to each other but animal was still off-feed. The gelding was gently led through a distance of about 30 meters into a riding arena of about 200 meters x 200 meters size, with low lush grass and located in the centre of the horse keeping facility. This

Table. 1: Observed Daily Vital Parameters

\begin{tabular}{|c|c|c|c|c|}
\hline Days & $\begin{array}{l}\text { Time of Examination } \\
\text { (hours) }\end{array}$ & $\begin{array}{c}\text { Respiratory rate (Circles/minute) } \\
\text { Observed Daily } \\
\text { Mean }\end{array}$ & $\begin{array}{l}\text { Pulse rate (beats/minute) } \\
\text { Observed Daily } \\
\text { Mean }\end{array}$ & $\begin{array}{c}\text { Rectal Temperature }\left({ }^{\circ} \mathrm{C}\right) \\
\text { Observed Daily } \\
\text { Mean }\end{array}$ \\
\hline \multirow{15}{*}{$\begin{array}{l}\text { Day } 0 \\
\text { Day } 1 \\
\text { Day } 2 \\
\text { Day } 3 \\
\text { Day4 } \\
\text { Day5 }\end{array}$} & 00 & 103 & 97 & 38.9 \\
\hline & 05: 00 & 90 & 82 & 38.8 \\
\hline & 10: 00 & 83 & 64 & $38.6 \quad 38.8$ \\
\hline & $24: 00$ & 22 & 64 & 38.6 \\
\hline & 29:00 & 72 & 68 & 39.0 \\
\hline & $34: 00$ & 43 & 54 & $38.7 \quad 38.8$ \\
\hline & 48:00 & 24 & 56 & 38.2 \\
\hline & $53: 00$ & 72 & 64 & 37.6 \\
\hline & $58: 00$ & 52 & 63 & $38.4 \quad 38.1$ \\
\hline & $72: 00$ & 45 & 56 & 38.4 \\
\hline & $82: 00$ & 46 & 56 & $38.5 \quad 38.5$ \\
\hline & $96: 00$ & 45 & 69 & 38.2 \\
\hline & 106:00 & 44 & 68 & $38.5 \quad 38.4$ \\
\hline & $120: 00$ & 40 & 68 & 38.5 \\
\hline & 130:00 & 41 & 66 & $38.4 \quad 38.4$ \\
\hline
\end{tabular}

Normal (Resting Values) temperature $\left(37.2-38.3^{\circ} \mathrm{C}\right)$, Heart rate $(28-44$ beats $/ \mathrm{min})$, Breathing rate $(10-24$ beats/min) of Adult horses [7]. 
By days-1, 2, 3 and 4 post-commencement of treatment, values of vital signs had declined but not normalize. The gelding walked around in the riding arena, groaned, grinded its teeth, was intermittently recumbent and looked at the abdomen.

Muscle twitch around the shoulders was absent and gait was balanced as the horse walked around in paddock. The gelding grazed but was off concentrate feed.

By day5, the gelding was observed to lay on lateral recumbency intermittently, assumed 'dog-sitting' position and rotated continually but gently through 360 degrees $\left(360^{\circ}\right)$ before it finally rose unaided.

Red spots were observed on the medial aspects of the thighs (groin) bilaterally and a floating chip of bone was palpable on the left knee. At this point, a specialist was invited from Veterinary Teaching Hospital, Ahmadu Bello University, Zaria, Nigeria, about $86 \mathrm{~km}$ from the academy stable in Kaduna city. For logistic difficulties, the specialist's visit was scheduled for the next (6th) day but the gelding was found dead in the early hours of day 6 .

\subsection{Postmortem Findings}

Gross findings were; copious urine and bruises sustained during struggle before death. Subcutaneous tissue, thoracic muscles and internal organs were jaundiced.

Thorax; Simple un-displaced fractures at proximal 3rd of 2 nd to 18 th ribs (total of 17 ribs) in the left hemithorax. Zone of fracture appeared dark due to hemorrhage collected between ribs and periosteum. Perioteum appeared intact but all affected ribs shattered at the fracture lines as slight pressure was applied on the left hemithorax (Plate 1)

Right (far) hind-limb; stifle and thigh muscles were were haemorrhagic. Patella ligaments were ruptured with blood clots (Plate 2).

Left (Near) hind-limb; Thigh muscles were haemorrhagic, patella was fractured and displaced (Plate 3).

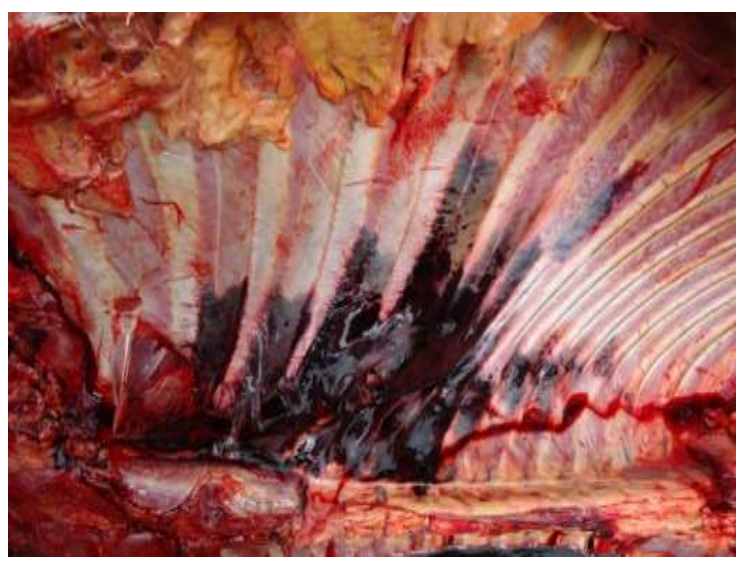

Plate 1: Zone of proximal $3^{\text {rd }}$ fracture of affected ribs 2 to 18 (dark zone) in right hemithorax

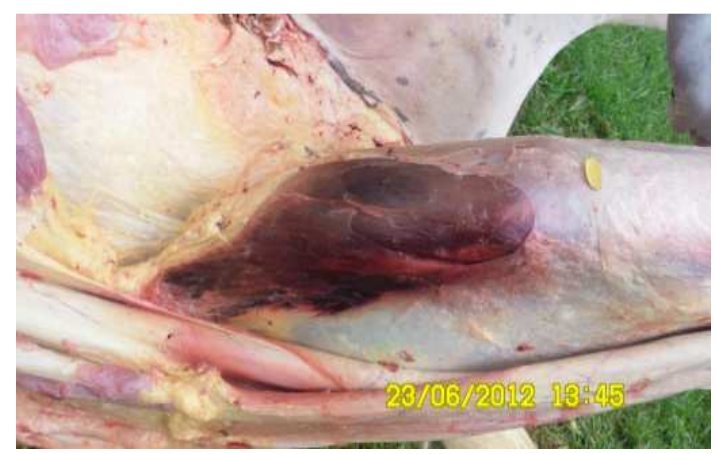

Plate. 2: Right stifle; Hemorrhagic due to blunt trauma of landing on concrete floor

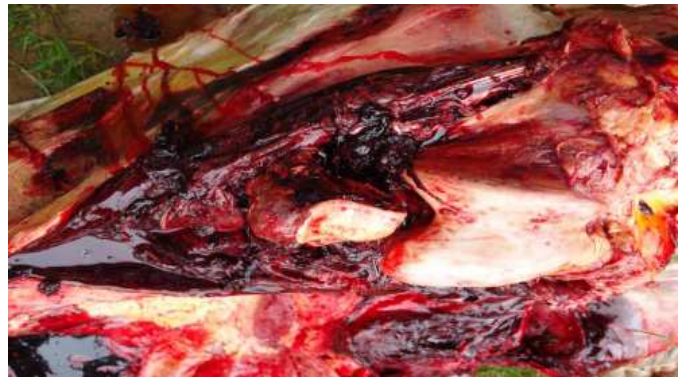

Plate. 3: Opened left stifle with Severe hemorrhage, fractured patella (arrow head) and patella chip (arrow)

\section{Discussion}

In this case, 17 ribs (except rib number 1) in the left hemithorax were fractured, un-displace and in a single plane, perhaps that was the reason that made the chest symmetry appeared normal. Flail chest is reported to results when two or more adjacent ribs are fractured in multiple planes $[5 ; 8]$. This made our diagnosis more difficult on the basis of clinical signs. The vital signs dropped from very high values at first observation gradually but remained at levels above normal until the gelding died in early hours of day 6 (Table 1). This may be due to the excruciating pain and inflammatory reaction at sites of injury resulting in cytokines release. The cytokines caused hyperthermia and in an effort for the body to loss heat, vasodilatation occurred in presence of hypovolemia already caused by internal hemorrhages resulting in hypotension. In a compensatory response, heart (pulse) and respiratory rates to improve blood flow and oxygen tension in blood respectively [9].

The Dexaphenylathrite ${ }^{\circledR}$ injection is an antiinflammatory, analgesic and anti-pyrexic preparation while Vitaflash ${ }^{\circledR}$ (multivitamins) has anti-stress effect [10]. The drugs were administered to reduce inflammation, pains and stress. The drugs' effects might have consequently brought down the vital parameters, gradually eliminated the muscle twitches around the shoulders and the restoration of locomotion. The unilateral fracture of the ribs of left hemithorax (Plate 1), the wider spread and severe soft tissues damages of the left stifle and the fractured left patella (Plate 3) compared to the right stifle (Plate 2) are indications that the left side of the horse's body had greater 
impact and traumatisation on ground than right side.

\section{Conclusion}

It was concluded that musculosketal injuries involving the thorax and stifle occur in adult horses following traumatic fall. At the time of accident horses with thoracic trauma may not exhibit signs that will lead to instant accurate diagnosis and such accidents are fatal. In conclusion, when an adult horse falls, thorough clinical examination, ultrasonography or less revealing radiography should be used in assessing thoracic and patella traumas. This will enable equine practitioners to plan early for conservative, surgical or medical management regime thereby reducing fatality.

\section{Acknowledgement}

We sympathize with the Commandant, Maj Gen CO Onwuamaegbu of Nigerian Defence Academy on the death of this parade horse. He approved and funded the acquisition of the highly priced and promising parade gelding. Our sympathy also is to the Academy Adjutant, Lt Col MI Abdulkadir who was the official rider of the horse and the Officer-In-Charge of Equitation Wing, Lt Col DD Kurmi who was the official custodian of the horse, over the sudden loss.

\section{References}

[1] Holcombe SJ, Laverty S. Thoracic trauma. In: Auer JA, Stick JA, eds. Equine Surgery. Philadelphia: WB Saunders,
$1999 ; 382-385$.

[2] Jean D, Picandet V, Macieira S, Beauregard G, D'Anjou MA, Beauchamp G. Detection of rib trauma in newborn foals in an equine critical care unit: a comparison of ultrasonography, radiography and physical examination. Equine Vet J. 2007; 39(2):158-

[3] Hassel DM. Thoracic trauma in horses. Vet Clin North Am equine Pract. 2007;23:67-80.

[4] Pablo T, Ana M, Francisco C, Cristina R, Diana MH. Rib fracture in a horse during an endurance race. Can Vet $\mathrm{J}$. (2011);52(11): 1226-1227

[5] Laverty S, Lavoie JP, Pascoe JR, Ducharme NG. Penetrating wounds of the thorax in 15 horses. Equine Vet $\mathrm{J}$ 1996;28(3):220-224.

[6] Rolfe M R, Norm GD, Thomas JD, Robin DG. Treating Thoracic Injuries. CE Article 1. Compendium Equine: Continuing Education for Veterinarians. pp.208-223. | Available at: www.CompendiumEquine.com 2009; Accessed on 8/2/2013 at 11.26 GMT.

[7] Dwyer R. Normal temperature, heart rate, breathing rate (resting values). Adult horses. http://www.thehorse.com/tools/normal-temperature-heartrate-breathing. 2013; Accessed 20/02/2013: 9:43GMT.

[8] Spackman CJA, Caywood DD. Management of thoracic trauma and chest wall reconstruction. Vet Clin North Am Small Anim Pract 1987;17(2):431-447

[9] Elgert KD. Immunology; Understanding the immune system. Wiley-Liss, Inc., U.S.A; 1996; 291-314.

[10] Aliu YO. Nigerian Veterinary Formulary; Handbook of Essential Veterinary Drugs, Biologics and Pesticide Chemicals. 1st ed. Veterinary Council of Nigeria; 2007;67pp. 